\title{
Effect of water-soluble polymers, polyethylene glycol and poly(vinylpyrrolidone), on the gelation of aqueous micellar solutions of Pluronic copolymer F127
}

Article

Accepted Version

Ricardo, N. M.P.S., Ricardo, N. M.P.S., Costa, F. d. M.L.L., Bezerra, F. W.A., Chaibundit, C., Hermida-Merino, D., Greenland, B., Burattini, S., Hamley, I. W., Nixon, S. K. and Yeates, S. G. (2012) Effect of water-soluble polymers, polyethylene glycol and poly(vinylpyrrolidone), on the gelation of aqueous micellar solutions of Pluronic copolymer F127. Journal of Colloid and Interface Science, 368 (1). pp. 336-341. ISSN 0021-9797 doi: https://doi.org/10.1016/j.jcis.2011.10.062 Available at https://centaur.reading.ac.uk/26075/

It is advisable to refer to the publisher's version if you intend to cite from the work. See Guidance on citing.

To link to this article DOI: http://dx.doi.org/10.1016/j.jcis.2011.10.062

Publisher: Elsevier

All outputs in CentAUR are protected by Intellectual Property Rights law, 
including copyright law. Copyright and IPR is retained by the creators or other copyright holders. Terms and conditions for use of this material are defined in the End User Agreement.

\section{www.reading.ac.uk/centaur}

\section{CentAUR}

Central Archive at the University of Reading

Reading's research outputs online 


\section{Effect of Water-Soluble Polymers, Polyethylene glycol and Poly(vinylpyrrolidone), on the Gelation of Aqueous Micellar Solutions of Pluronic Copolymer F127}

Nágila M. P. S. Ricardo, ${ }^{a *}$ Nadja M. P. S. Ricardo, ${ }^{a}$ Flávia de M. L. L. Costa, ${ }^{a}$ Francisco W.

A. Bezerra, ${ }^{\mathrm{a}}$ Chiraphon Chaibundit, ${ }^{*}$ Daniel Hermida-Merino, ${ }^{\mathrm{c}}$ Barnaby W. Greenland, ${ }^{\mathrm{d}}$ Stefano Burattini, ${ }^{\mathrm{d}}$ Ian W. Hamley, ${ }^{\mathrm{d}}$ S. Keith Nixon ${ }^{\mathrm{e}}$ and Stephen G. Yeates ${ }^{\mathrm{e}}$

${ }^{a}$ Department of Organic and Inorganic Chemistry, Polymer Laboratory, Federal University of Ceará CX 12200 Fortaleza, Brazil.

${ }^{b}$ Department of Materials Science and Technology, Faculty of Science, Prince of Songkla University, Hat Yai, Songkhla, 90112 Thailand.

c ESRF, 6 rue Jules Horowitz BP220, 38043 Grenoble, Cedex 9, France.

d Department of Chemistry, University of Reading, Reading RG6 6AD, UK.

e School of Chemistry, University of Manchester, Manchester M13 9PL, UK.

* Corresponding authors.

E-mail: naricard@ufc.br (Nágila M.P.S Ricardo),

Tel.: +55 8533669367 and Fax: +55 8533669978

E-mail: chiraphon.c@psu.ac.th (C. Chaibundit)

Tel. and Fax: +66 74446925 


\begin{abstract}
The micellization of $\mathrm{F} 127\left(\mathrm{E}_{98} \mathrm{P}_{67} \mathrm{E}_{98}\right)$ in dilute aqueous solutions of polyethylene glycol (PEG6000 and PEG35000) and poly(vinylpyrrolidone) (PVP K30 and PVP K90) is studied. The average hydrodynamic radius $\left(\mathrm{r}_{\mathrm{h}, \mathrm{app}}\right)$ obtained from the dynamic light scattering technique increased with increase in PEG concentration but decreased on addition of PVP, results which are consistent with interaction of the micelles with PEG and the formation of micelles clusters, but no such interaction occurs with PVP. Tube inversion was used to determine the onset of gelation. The critical concentration of F127 for gelation increased on addition of PEG and of PVP K30 but decreased on addition of PVP K90. Small-angle X-ray scattering (SAXS) was used to show that the $30 \mathrm{wt} \% \mathrm{~F} 127$ gel structure (fcc) was independent of polymer type and concentration, as was the $d$-spacing and so the micelle hardsphere radius. The maximum elastic modulus $\left(\mathrm{G}^{\prime}{ }_{\max }\right)$ of $30 \mathrm{wt} \% \mathrm{~F} 127$ decreased from its value for water alone as PEG was added, but was little changed by adding PVP. These results are consistent with the packed-micelles in the $30 \mathrm{wt} \% \mathrm{~F} 127$ gel being effectively isolated from the polymer solution on the microscale while, especially for the PEG, being mixed on the macroscale.
\end{abstract}

Keywords $\quad$ F127, water soluble polymer, micelle, gel, modulus 


\section{Introduction}

Pluronic poly(ethylene oxide)-poly(propylene oxide)-poly(ethylene oxide) copolymers are available across a range of compositions [1]. We use the notation $\mathrm{E}_{m} \mathrm{P}_{n} \mathrm{E}_{m}$, where $\mathrm{E}=$ oxyethylene, $\mathrm{OCH}_{2} \mathrm{CH}_{2}, \mathrm{P}=$ oxypropylene, $\mathrm{OCH}_{2} \mathrm{CH}\left(\mathrm{CH}_{3}\right)$, and subscripts $m$ and $n$ to denote number-average block lengths in repeat units. Micellar gels (hard gels) which form on warming moderately-concentrated aqueous solutions of these copolymers, so-called cold gelation, were reported in the 1960s [2], and those of Pluronic F127 (nominal formula $\mathrm{E}_{98} \mathrm{P}_{67} \mathrm{E}_{98}$ ) warmed from ambient were proposed for treatment of burns in 1972 [3]. Quantitative study of the release of a solubilized drug from F127 gel followed [4], since when a wide range of pharmaceutical applications of F127 have been explored [5].

F127 in water forms a hard gel at concentrations in the range $15-50 \mathrm{wt} \%$ and at temperatures above $5{ }^{\circ} \mathrm{C}[6]$. Small-angle neutron scattering (SANS) and/or small-angle Xray scattering (SAXS) have been used to identify body-centred cubic (bcc) [7], face-centred cubic (fcc) [8], and hexagonal close packed (hcp) gels [9], this last related to shear history. It has been shown that aqueous gels of purified F127 are fcc close to the gel/fluid boundary but bcc within the gel phase, while gels prepared from impure F127 (used as received) are fcc throughout [10].

This last observation is consistent with reports that the formation of cubic micellar gels of F127 is affected by the addition of polyethylene glycol (PEG) in the range $M_{\mathrm{n}}=2000$ $20000 \mathrm{~g} \mathrm{~mol}^{-1}\left(\mathrm{E}_{44}-\mathrm{E}_{440}\right)[11,12]$. The temperature at which gel forms is significantly increased, the effect being greater the longer the PEG chain length. For example, Malmsten and Lindman [12] report gelation temperatures for $25 \mathrm{wt} \%$ F127 solution of ca. $23{ }^{\circ} \mathrm{C}$ (water), $25{ }^{\circ} \mathrm{C}\left(2 \mathrm{wt} \%\right.$ PEG6000) and $33{ }^{\circ} \mathrm{C}(2 \mathrm{wt} \%$ PEG20000), and found that no gel is formed on heating the solution if the PEG20000 concentration is increased beyond $2.5 \mathrm{wt} \%$. The addition of PEG400 and PEG600, investigated under comparable conditions, had little 
effect on gelation.

We have found no accounts in the literature of the effect of added water-soluble poly(vinylpyrrolidone) on the gelation of F127 which can be compared with those described above for PEG. Recent results [13], which are confirmed by this report, point to contrasting effects of addition of PVP and PEG when added to dilute (1 wt \%) micellar solutions of F127 and related copolymers. Association of PEG with the E-blocks of the micelle coronae is favored and leads to formation of micelle clusters. In contrast [14], the interaction of PVP with coronal E-blocks has been shown to be enthalpically neutral and association is restricted. Accordingly, in this paper we report an investigation of the gelation of aqueous solutions of F127 of adding poly(vinylpyrrolidone), either PVP K30 or PVP K90. Comparison is made with the effect of adding PEG6000 or PEG35000. Dynamic light scattering from dilute solutions was used to check micellization. Gel boundaries were defined by tube inversion (TI) and checked by oscillatory shear rheometry, thus distinguishing hard gel (immobile in the TI test) from soft gel (mobile but with raised elastic modulus). Elastic and viscous moduli were measured within the temperature range $5-85^{\circ} \mathrm{C}$, and SAXS was used to check the structure of $30 \mathrm{wt} \% \mathrm{~F} 127$ gels held at $30{ }^{\circ} \mathrm{C}$. 


\section{Experimental}

\subsection{Materials.}

Triblock copolymer F127, a product of BASF Corp. purchased from Sigma, was used as received. The value of the number-average molar mass supplied with the sample was $12500 \mathrm{~g} \mathrm{~mol}^{-1}$. A value of the ratio of weight- to number-average molar mass, $M_{\mathrm{W}} / M_{\mathrm{n}}=$ 1.20 , was determined by gel permeation chromatography (GPC) using $N, N$ dimethylacetamide at $70{ }^{\circ} \mathrm{C}$ as solvent and the method described previously [15]. The polymers were used as received, PEG6000 and PEG35000 obtained from Aldrich and PVP K30 and PVP K90 from obtained from Fluka. Using manufacturer's data, PEG6000 and PEG35000 have $M_{\mathrm{n}} \approx 6000$ and $35000 \mathrm{~g} \mathrm{~mol}^{-1}$ respectively and narrow chain length distributions: our own check by GPC with DMA solvent at $70^{\circ} \mathrm{C}$ and poly(ethylene oxide) calibrants yielded distribution widths of $M_{\mathrm{w}} / M_{\mathrm{n}}=1.07$ (PEG6000) and 1.16 (PEG35000). A similar check of the distribution widths of PVP K30 (nominally $M_{\mathrm{w}}=40000 \mathrm{~g} \mathrm{~mol}^{-1}$ ) and PVP K90 (nominally $M_{\mathrm{w}}=360000 \mathrm{~g} \mathrm{~mol}^{-1}$ ), using GPC with DMA/LiNO 3 solvent at $70{ }^{\circ} \mathrm{C}$ and poly(ethylene oxide) calibrants, gave values of $M_{\mathrm{w}} / M_{\mathrm{n}}=2.8$ (PVP K30) and 3.6 (PVP K90). Adopting the manufacturers values of $M_{\mathrm{w}}$ our values of $M_{\mathrm{w}} / M_{\mathrm{n}}$ lead to $M_{\mathrm{n}} \approx 14000$ and $100000 \mathrm{~g} \mathrm{~mol}^{-1}$ for PVP K30 and PVP K90 respectively.

\subsection{Dynamic Light Scattering.}

Solutions were filtered through Millipore Millex filters (Triton free, $0.22 \mu \mathrm{m}$ ) directly into the cleaned scattering cell. In certain experiments, the most concentrated solution was filtered and subsequently diluted with filtered water. Dynamic light scattering (DLS) measurements were made using a Brookhaven BI9000AT digital correlator to acquire data. The duration of the experiment was $10 \mathrm{~min}$, and each experiment was repeated two or more times. Scattered light intensity was measured at $\theta=90^{\circ}$ to the incident beam. 
The correlation functions from DLS were analyzed by the constrained regularized CONTIN method [16] to obtain distributions of decay rates $(I)$, hence distributions of apparent mutual diffusion coefficient $\left[D_{\mathrm{app}}=\Gamma / q^{2}, q=(4 \pi n / \lambda) \sin (\theta / 2), n=\right.$ refractive index of the solvent, $\lambda=$ wavelength] and ultimately of apparent hydrodynamic radius $\left(r_{\mathrm{h}, \text { app }}\right.$, radius of the hydrodynamically equivalent hard sphere corresponding to $D_{\text {app }}$ ) via the StokesEinstein equation.

$$
r_{\mathrm{h}, \mathrm{app}}=k T /\left(6 \pi \eta D_{\mathrm{app}}\right)
$$

where $k$ is the Boltzmann constant and $\eta$ is taken to be the viscosity of the water at temperature $T$. In practice, intensities $I(I)$ delivered by the CONTIN program at logarithmically spaced values of the decay rate were transformed to $I(\log \Gamma)=I(\Gamma) \Gamma$ to obtain intensity distributions of $\log (\Gamma)$ and hence of $\log \left(r_{\mathrm{h} \text {,app }}\right)$. Normalization of $I\left(\log r_{\mathrm{h} \text {,app }}\right)$ gave the intensity fraction distributions presented in Section 3.1. Values of $r_{\mathrm{h}, \text { app }}$ averaged over the intensity distribution were also delivered by the program.

\subsection{Turbidity and Gelation.}

Onset temperatures of turbidity and gelation were measured to $\pm 1{ }^{\circ} \mathrm{C}$ by enclosing samples of aqueous solutions ( $0.5 \mathrm{~g})$ in small tubes and observing while heating them slowly $\left(0.1{ }^{\circ} \mathrm{C} \mathrm{min}^{-1}\right)$ in a water bath through the temperature range $5-90{ }^{\circ} \mathrm{C}$. Gelation was recognized by immobility of the solution when the tube was inverted at intervals of $1{ }^{\circ} \mathrm{C}$.

\subsection{Rheometry.}

Samples were prepared in small vials and stored for at least one week at $5{ }^{\circ} \mathrm{C}$ to reach equilibrium. A strain-controlled ARES rheometer (TA Instruments) with cone-and-plate geometry (diameter $50 \mathrm{~mm}$, angle $0.04 \mathrm{rad}$ ) and with Peltier control of plate temperature $\left( \pm 0.1{ }^{\circ} \mathrm{C}\right)$ was used in oscillatory-shear mode at frequency $f=1 \mathrm{~Hz}$ to determine elastic $\left(G^{\prime}\right)$ 
and loss $\left(G^{\prime \prime}\right)$ moduli as the samples were heated from $5{ }^{\circ} \mathrm{C}$ at $1{ }^{\circ} \mathrm{C} \min ^{-1}$. The strain amplitude was held at a low value $(A=0.005)$, thus ensuring that measurements of $\mathrm{G}^{\prime}$ and $\mathrm{G}^{\prime \prime}$ were in the linear viscoelastic region. A solvent trap maintained a solvent-saturated atmosphere around the cell, but evaporation of solvent from the edge of the cone-and-plate cell limited measurements to temperatures below $80-85^{\circ} \mathrm{C}$. Each experiment was repeated twice.

\subsection{Small-angle X-ray Scattering.}

Experiments for $30 \mathrm{wt} \%$ F127 aqueous gel plus PEG35000, PVP K30 and PVP K90 were performed on beamline I-711 at MAX-lab, Lund, Sweden. The wavelength was $1.07 \AA$ and the sample-detector distance was $1.44 \mathrm{~m}$. The data were collected using a CCD detector (MAR CCD $165 \mathrm{~mm}$ active area; 79×79 microns pixel resolution). The wavenumber scale ( $q$ $=4 \pi \sin \theta / \lambda$, scattering angle $=2 \theta$, wavelength $\lambda=1.033 \AA$ ) was calibrated with silver behenate. The capillaries were mounted in a six-position holder thermostated by a watercirculation bath (Julabo F12-MC) which was remotely controlled.

Additional SAXS experiments for $30 \mathrm{wt} \%$ F127 aqueous gel plus PEG6000 were performed on beamline BM26 (DUBBLE) at the ESRF, Grenoble, France. The X-ray wavelength was $1.033 \AA$ and the SAXS sample-to-detector distance was $4 \mathrm{~m}$. The $q$ scale was calibrated with collagen. Samples were mounted in a custom designed brass sample holder within an O-ring between mica sheets. Temperature control was achieved via a recirculating water bath, and the gels were held at constant temperature for $15 \mathrm{~min}$ before exposure. SAXS patterns were collected with a multiwire area detector and reduced to onedimensional form by sector integration. 


\section{Results and Discussion}

\subsection{Hydrodynamic radii.}

Intensity fraction distributions of $\log \left(r_{\mathrm{h}, \text { app }}\right)$ were obtained for dilute solutions of F127 in PEG6000/water, PEG35000/water, PVP K30/water and PVP K90/water. Since F127 is known to be incompletely micellized in solutions of low concentration at temperatures of 30 ${ }^{\circ} \mathrm{C}$ or lower, the solution temperatures for DLS were held at 40 or $50{ }^{\circ} \mathrm{C}$. The distributions obtained for aqueous solutions at $40{ }^{\circ} \mathrm{C}$ containing $1 \mathrm{wt} \% \mathrm{~F} 127$ and four concentrations of either PEG35000 or PVP K90 are shown in Fig. 1. Similar plots for PEG6000 and PVP K30 are presented in the Supplementary Material associated with this paper. As illustrated in Fig. 1 , the intensity distributions shifted to higher values of $r_{\mathrm{h}, \text { app }}$ as the concentration of PEG35000 was increased and to lower values of $r_{\mathrm{h}, \mathrm{app}}$ as the concentration of PVP K90 was increased. Similar results were obtained at solution temperatures of $50{ }^{\circ} \mathrm{C}$.
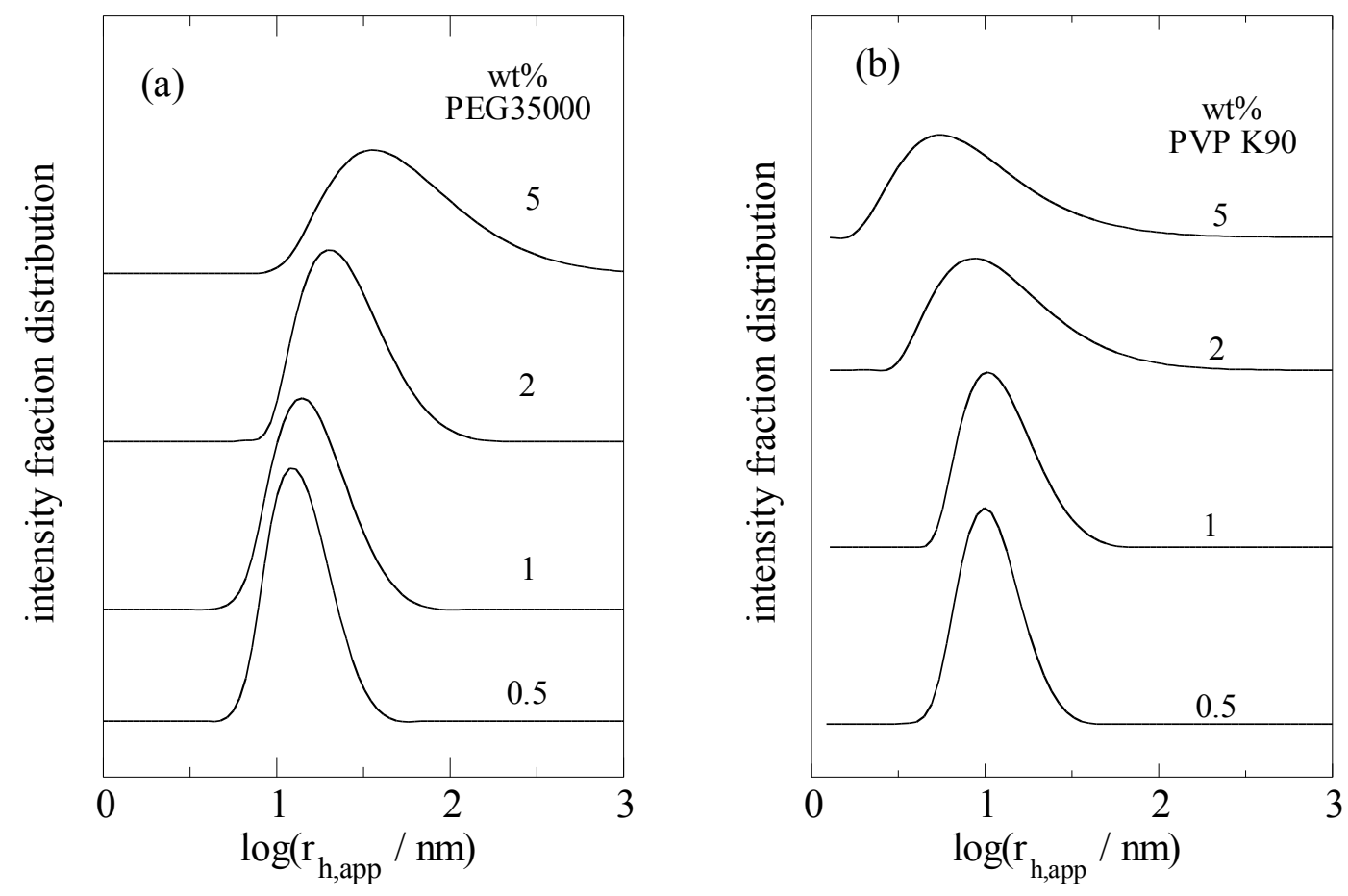

Fig. 1. Intensity fraction distributions of $\log \left(r_{\mathrm{h}, \text { app }}\right)$ for $1 \mathrm{wt} \%$ solutions of $\mathrm{F} 127$ in solutions of (a) PEG35000 and (b) PVP K90. Polymer concentrations (wt\%) are indicated. $T=40{ }^{\circ} \mathrm{C}$. 

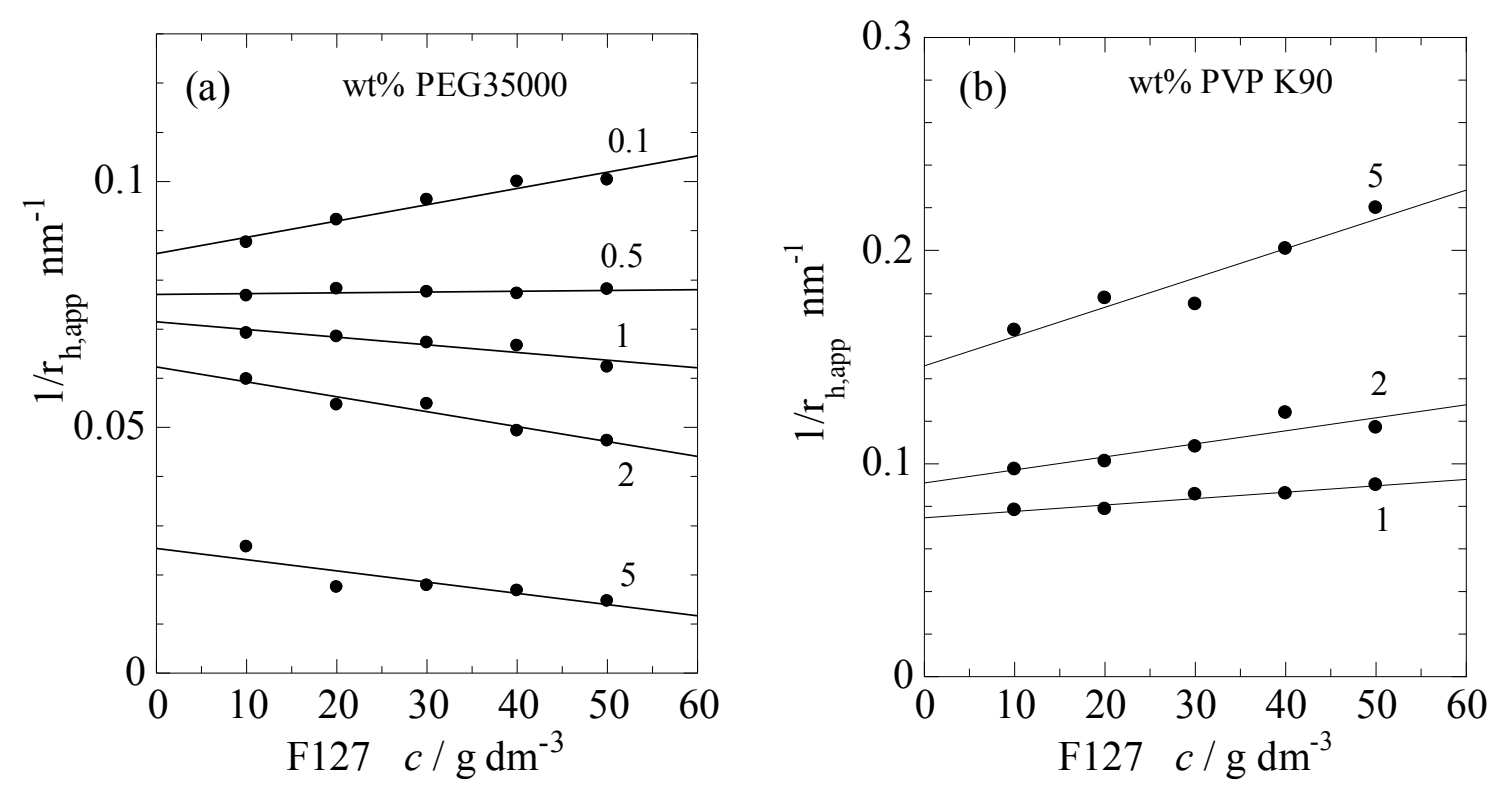

Fig. 2. Concentration dependence of the reciprocal of the apparent hydrodynamic radii for solutions of F127 in solution in (a) PEG35000 and (b) PVP K90. Polymer concentrations (wt $\%$ ) are indicated. $T=40{ }^{\circ} \mathrm{C}$.

Intensity-average values of $r_{\mathrm{h} \text {,app }}$ (through eqn. 1 proportional to the apparent intensity-average diffusion coefficient) were delivered by the CONTIN program. For both F127/PEG and F127/PVP systems we chose to use the viscosity of pure water in the CONTIN program, so that the averages delivered included all species present: micelles, clusters, polymer chains, etc. For F127 and PEG the major contribution to the radius was from micelle/polymer associates in water, with contributions from PEG chains contributing very little to the intensity-weighted average. For F127 and PVP where, as discussed below, the single distributions defined by DLS were mixtures of micelles and polymer chains, the intensity average was still determined largely by the micelles.

The corresponding values of $1 / r_{\mathrm{h}}$,app were plotted against concentration. Examples for solutions of PEG35000 and PVP K90 are illustrated in Fig. 2. The increase in value of average $r_{\mathrm{h} \text {,app }}$ at a constant concentration of PEG35000 as the F127 concentration is increased is illustrated by negative slopes of the plots for 1, 2 and 5 wt\% PEG35000 in Fig. 
2a. The plot for $0.1 \mathrm{wt} \%$ PEG35000 is included in Fig. 2a as evidence that the usual increase in $1 / r_{\mathrm{h} \text {,app }}$ with increase in copolymer concentration holds at very low concentrations of PEG35000, while the plot for 0.5 wt $\%$ PEG35000 with almost zero slope marks a transition in behavior. In contrast, the plots for 1, 2 and $5 \mathrm{wt} \%$ PVP K90 solutions shown in Fig. $2 \mathrm{~b}$ all have positive slopes, as expected for micellar solutions of F127, as do those for lower PVP K90 concentrations which overlap the plots for $1 \mathrm{wt} \%$ polymer and are not shown in Fig. $2 \mathrm{~b}$.

The increase in the value of average $r_{\mathrm{h}, \text { app }}$ at a given concentration of F127 as PEG35000 concentration is increased and the corresponding decrease in average $r_{\mathrm{h} \text {,app }}$ as PVP K90 concentration is increased is generalized for all four polymers in Fig.3 in which values of $r_{\mathrm{h} \text {,app }}$ at zero F127 concentration, obtained from plots similar to those illustrated in Fig. 2 for all four polymers and at $40{ }^{\circ} \mathrm{C}$ and $50{ }^{\circ} \mathrm{C}$, are plotted against polymer concentration. The curves intersect the ordinate at $r_{\mathrm{h}} \approx 13 \mathrm{~nm}$, the value expected for F127 alone in water at $40-50{ }^{\circ} \mathrm{C}$ [6b]. It is seen that the effects of addition of PEG 35000 and PVP K90 noted for solutions at $T=40{ }^{\circ} \mathrm{C}$ and illustrated in Figs. 1 and 2 hold equally well for solutions at $50{ }^{\circ} \mathrm{C}$, that the effect of adding PEG6000 is similar to that of adding PEG35000 though smaller in magnitude, and that addition of PVP K30 has much the same effect as addition of PVP K90. 


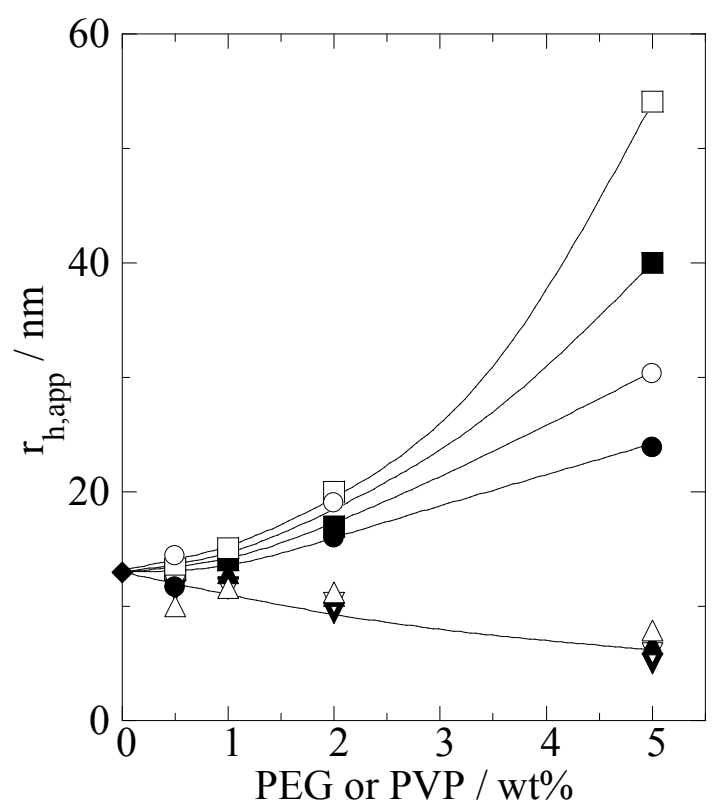

Fig. 3. Average hydrodynamic radii obtained for aqueous solutions of F127 and $(\bullet, \bigcirc)$ PEG6000, $(\boldsymbol{\square}, \square)$ PEG35000, $(\boldsymbol{\nabla}, \nabla)$ PVP K30 and $(\boldsymbol{\Delta}, \triangle)$ PVP K90. Filled symbols denote $T$ $=40{ }^{\circ} \mathrm{C}$, unfilled symbols $T=50{ }^{\circ} \mathrm{C}$. The curves are intended to lead the eye through the points.

The increase in average values of $r_{\mathrm{h} \text {,app }}$ resulting from the presence of PEG in solutions of F127 can be understood by noting that PEG is compatible with the E-blocks of the micelle corona. This implies that the poly(ethylene oxide) solution in the micelle corona is favored as an environment for the PEG chains when compared with water, and consequent association of added PEG with the micelles leads to bridging between micelles to form clusters and necklace-like structures, as reported for related systems $[17,18]$ and reviewed by Tam and Wyn-Jones [19]. The observation that average values of $r_{\mathrm{h} \text {,app }}$ increases with increase in F127 concentration in the presence of PEG is consistent with increased clustering.

In contrast PVP is incompatible with the E-blocks of the micelle corona and overlap with the micelle corona is restricted. Indeed coincidence of enthalpy changes detected by isothermal titration calorimetry of micellar solutions of copolymer $\mathrm{C}_{12} \mathrm{E}_{6}$ with and without added PVP K90 [14] indicates that interaction of PVP with the E blocks in the micelle 
coronae is enthalpically neutral. The shift of the intensity distribution to lower values of $\log \left(r_{\mathrm{h}, \text { app }}\right)\left(\right.$ Fig. 1) on addition of PVP, and the consequent decrease in values of $r_{\mathrm{h}}$ (Fig. 3) can be assigned to the micelles maintaining their separate identity and the increase in the proportion of chains included within the main peak taking the intensity average to smaller values.

\subsection{Gel diagrams}

Regions of gel and mobile solution determined by tube inversion are shown in Fig. 4 for F127 in water and in solutions containing up to $5 \mathrm{wt} \%$ of PEG35000, PVP K30 and PVP K90, and up to $10 \mathrm{wt} \%$ for PEG6000. Clear and turbid phases are not shown in this figure, nor is the phase separation observed for gels containing $5 \mathrm{wt} \%$ PVP K30 or PVP K90: these features are discussed in Section 3.3. Related data for F127 with PEG6000 or PEG20000 have been reported by Malmsten and Lindman [12].

Values of the critical concentration for gel formation (cgc) taken from Fig. 4 are plotted against polymer concentration in Fig. 5a. Temperatures at the critical points fell in the range $43-49{ }^{\circ} \mathrm{C}$ with, except for PVP K90, a tendency to increase with increase in polymer concentration. The effect of adding PEG6000 or PEG35000 to aqueous solutions of F127 was to increase the F127 concentration required to cause gelation from that in water alone ( $\operatorname{cgc} \approx 15.2 \mathrm{wt} \%$ ), to $\mathrm{cgc} \approx 24 \mathrm{wt} \% \mathrm{~F} 127$ for $5 \mathrm{wt} \%$ PEG35000 with a similar shift recorded for $10 \mathrm{wt} \%$ PEG6000. Addition of low concentrations of PVP K30 also increased the F127 concentration required to cause gelation, to $\mathrm{cgc} \approx 18 \mathrm{wt} \% \mathrm{~F} 127$ for $2 \mathrm{wt} \% \mathrm{PVP}$ K30, but without further increase at the higher value of $5 \mathrm{wt} \%$ PVP K30. Except for a marginal increase in the value of the cgc at concentrations below $1 \mathrm{wt} \%$, the effect of adding the high molar mass PVP K90 was to move the onset of gel formation to lower concentrations, e.g. to $12 \mathrm{wt} \% \mathrm{~F} 127$ for $5 \mathrm{wt} \%$ PVP K90. 

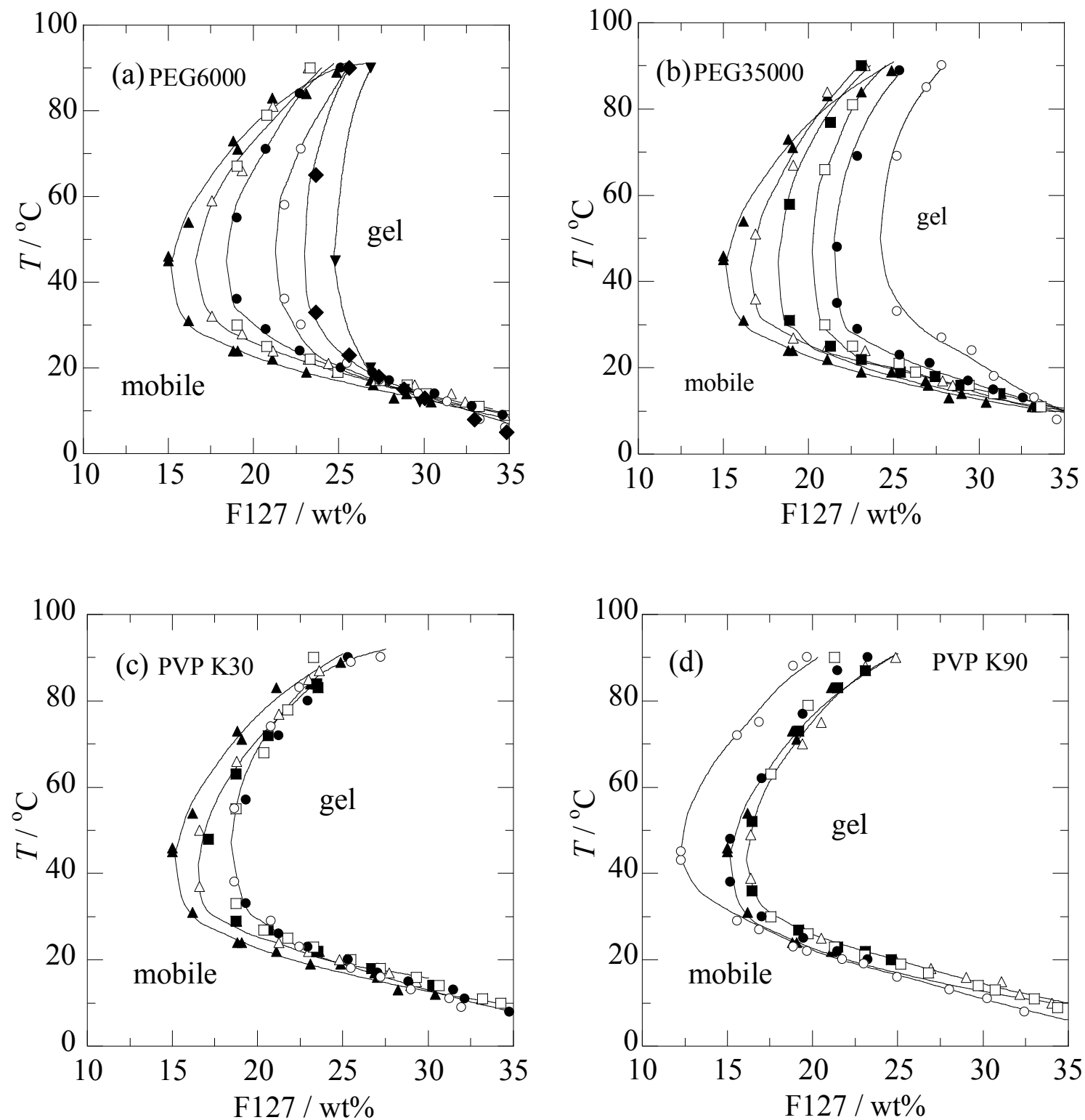

Fig. 4. Gel diagrams for solutions of copolymer F127 in water and in aqueous solutions of PEG6000, PEG35000, PVP K30 and PVP K90, as indicated. The results are from tube inversion: clear and turbid phases are not distinguished. Polymer concentrations in the range 0.1 to $10 \mathrm{wt} \%$ are indicated by $(\mathbf{\Delta})$ water alone, $(\triangle) 0.1 \mathrm{wt} \%,(\boldsymbol{\square}) 0.5 \mathrm{wt} \%$, ( $\square) 1 \mathrm{wt} \%$, $2 \mathrm{wt} \%$, (○) $5 \mathrm{wt} \%,(\diamond) 7 \mathrm{wt} \%$ and $(\nabla) 10 \mathrm{wt} \%$. Curves are drawn through all concentrations available for PEG35000 but, for clarity of presentation, through selected concentrations for the other three polymers. 

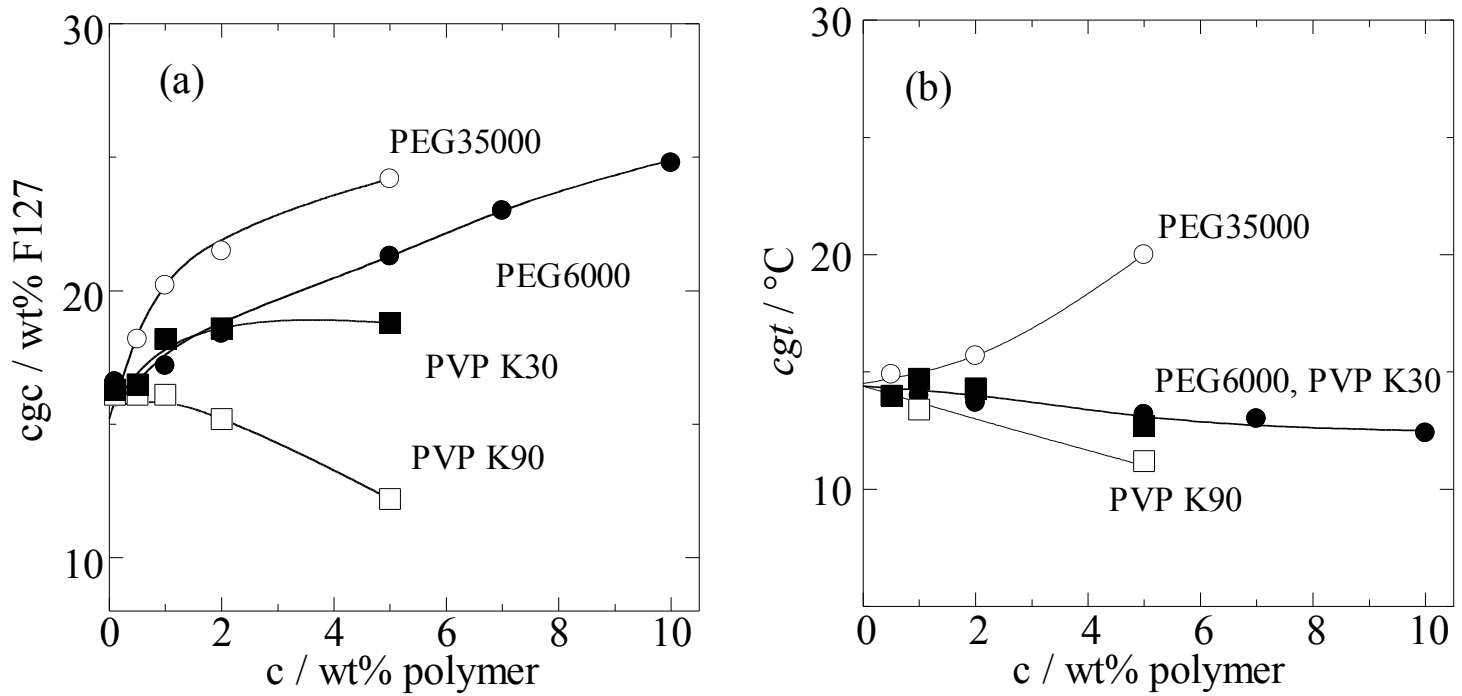

Fig. 5. The effect of added polymer on (a) values of the critical gel concentration (cgc) for aqueous solutions of copolymer F127 and (b) values of the critical gel temperature (cgt) for

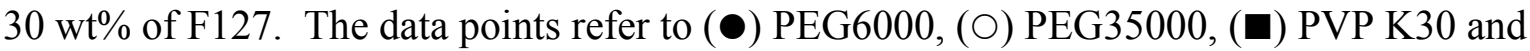
( $\square$ ) PVP K90.

Fig. $5 \mathrm{~b}$ illustrates values of critical temperatures for gelation (cgt) for solutions containing $30 \mathrm{wt} \% \mathrm{~F} 127$ and the various concentrations of the four polymers. The highest value observed was $20^{\circ} \mathrm{C}$, which confirms an ample margin for the SAXS investigation, described in Section 3.4, of the structure of $30 \mathrm{wt} \% \mathrm{~F} 127 /$ polymer gels at $30{ }^{\circ} \mathrm{C}$. 


\subsection{Turbidity and Phase Separation}

All the solutions of F127 with added PEG6000 were optically clear. Of the others, solutions with $1 \mathrm{wt} \%$ or more added PEG35000 and all solutions with added PVP (K30 or K90) showed regions of turbid gel, often with related regions of turbidity in the mobile phase. In particular, gels of F127 with 5 wt\% PVP K30 or PVP K90 phase separated. The relevant diagrams for PEG35000, PVP K30 and PVP K90 can be seen in the Supplementary Material associated with this paper, Figs. S2 to S4.

As discussed in Section 3.4, structures of the $30 \mathrm{wt} \% \mathrm{~F} 127$ gels at $30{ }^{\circ} \mathrm{C}$ were determined by SAXS. It is clear from Figs. 4 and $5 \mathrm{~b}$ the condition $30 \mathrm{wt} \% \mathrm{~F} 127$ and $30{ }^{\circ} \mathrm{C}$ lies well within the gel temperature range as, at that concentration, upper boundaries are above $90{ }^{\circ} \mathrm{C}$ and lower boundaries are in the range $10-20{ }^{\circ} \mathrm{C}$. Structures of both clear and turbid gels were investigated, but not those of the two phase-separated systems. 


\subsection{Gel Structure: $S A X S$}

A selection of SAXS profiles of samples of $30 \mathrm{wt} \% \mathrm{~F} 127$ gels at $30{ }^{\circ} \mathrm{C}$ are shown in Fig. 6. Four peaks or shoulders are seen in each profile, corresponding to reflections with values of the scattering vector in the sequence $q / q^{*}=1,1.155,1.633,1.915$ characteristic of the face-centred cubic (fcc) structure. The exception is the profile obtained for $2 \mathrm{wt} \% \mathrm{PVP}$ K90 which shows only a broad peak centred on $q \approx 0.43 \AA^{-1}$. Table 1 lists the samples for which satisfactory profiles were obtained, together with values of the scattering vector at the first-order reflection $\left(q^{*}\right)$, and corresponding values of the $d$ spacing calculated as $d=2 \pi / q^{*}$ and the micelle hard-sphere radius for the fcc structure calculated as $r_{\mathrm{hs}}=(d \sqrt{ } 6) / 4$. Given an experimental uncertainty in $q^{*}$ of $\pm 0.002 \AA^{-1}$, values of $d$ (range 150-161 $\AA$ ) and $r_{\mathrm{hs}}$ (range 92-98 A) are identical for all the gels listed in Table 1, whether clear or turbid. 
Table 1. SAXS: Gel structure, scattering vector $q^{*}, d$-spacing and micelle hard-sphere radius $\left(r_{\mathrm{hs}}\right)$ for $30 \mathrm{wt} \%$ gels of copolymer F127 in water and in aqueous solutions of the polymers. $\mathrm{T}=30^{\circ} \mathrm{C}$.

\begin{tabular}{ccccccc}
\hline \multirow{2}{*}{ water } & $\mathrm{wt} \%$ & gel & structure & $q^{* /} \AA^{-1}$ & $d / \AA$ & $\mathrm{r}_{\mathrm{hs}} / \AA$ \\
\hline PEG6000 & - & clear & $\mathrm{fcc}$ & 0.042 & 150 & 92 \\
& 2 & clear & fcc & 0.041 & 153 & 94 \\
& 5 & clear & fcc & 0.041 & 153 & 94 \\
& 7 & clear & fcc & 0.040 & 157 & 96 \\
PEG35000 & 10 & clear & fcc & 0.039 & 161 & 98 \\
& 0.1 & clear & fcc & 0.041 & 153 & 94 \\
& 0.5 & clear & fcc & 0.041 & 153 & 94 \\
& 1 & clear & fcc & 0.041 & 153 & 94 \\
PVP K30 & 2 & clear & fcc & 0.040 & 157 & 96 \\
& 5 & turbid & fcc & 0.042 & 150 & 92 \\
& 1 & turbid & fcc & 0.041 & 153 & 94 \\
& 2 & turbid & fcc & 0.041 & 153 & 94 \\
& 0.5 & fcc & 0.041 & 153 & 94 \\
& 0.1 & turbid & fcc & 0.042 & 150 & 92 \\
& 1 & turbid & fcc & 0.041 & 153 & 92 \\
\hline
\end{tabular}



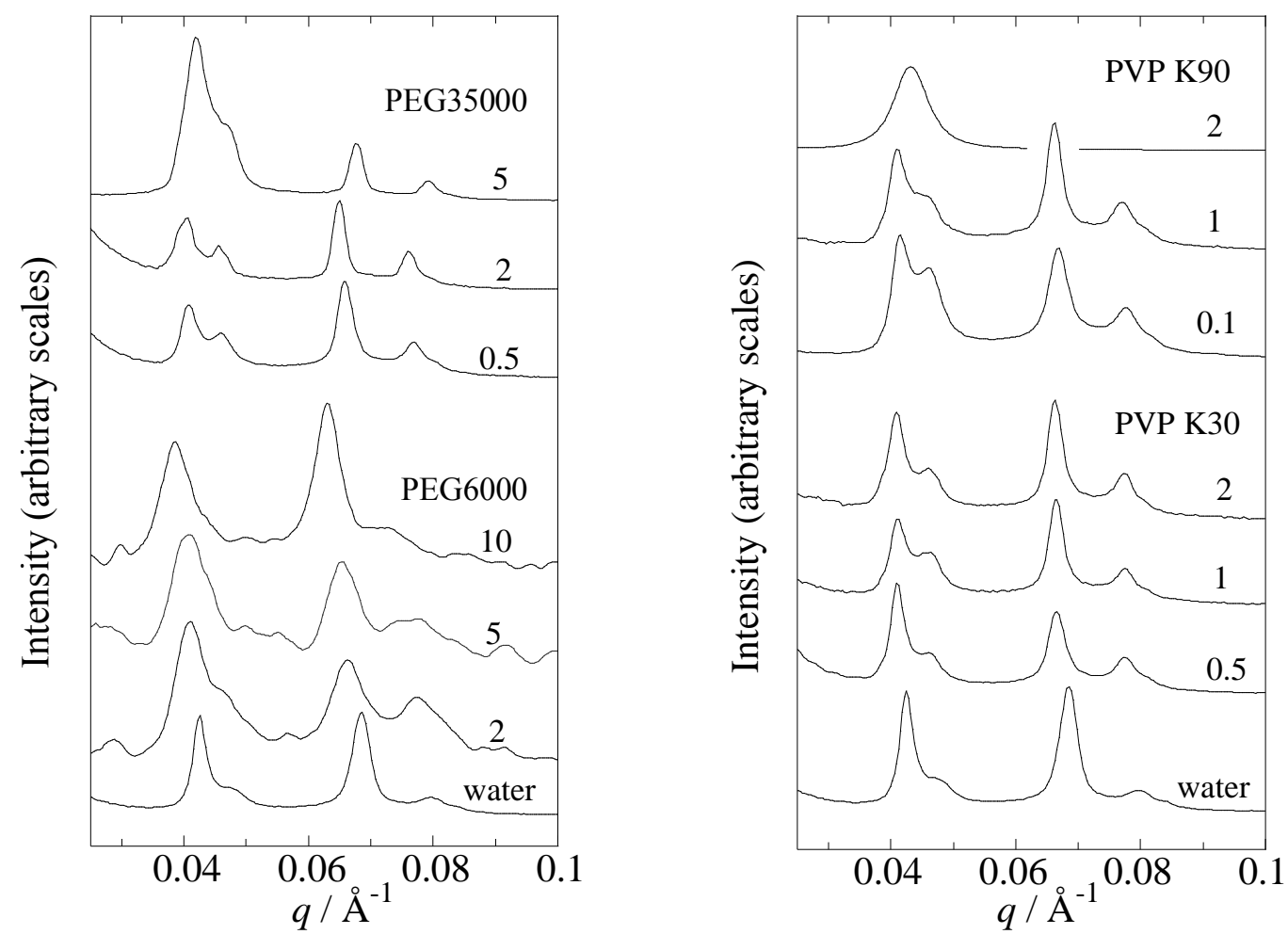

Fig. 6. Selected SAXS profiles for $30 \mathrm{wt} \%$ aqueous gels of F127 plus PEG6000, PEG35000, PVP K30 or PVP K90 as indicated. Values of wt\% polymer are shown. Intensity scales and zeros are arbitrary. 
The almost-constant value of $r_{\mathrm{hs}}$ derived from SAXS, average value $94 \mathrm{~nm}$, contrasts with the range of values of the hydrodynamic radius illustrated in Fig. $3\left(r_{\mathrm{h}}\right.$ in the range 6-54 $\mathrm{nm}$ ) and discussed in Section 3.1. This can be explained as follows. In a $30 \mathrm{wt} \%$ F127 gel the close-packed units can be thought of as micelle cores separated by a concentrated solution of the E-blocks of the micelle coronas. As discussed previously [20], in such a concentrated solution there is a very weak hydrophobic effect as indicated by the very low values measured under such conditions for the enthalpy of micellization. Equally, in concentrated solution there is little thermodynamic advantage in PEG associating with the micelle fringe as it does in dilute solution. Related to this, as discussed in Section 3.1, there is no possibility of PVP associating with the micelle fringe. Accordingly we conclude that polymer solution, whether of PEG or PVP, is effectively separated from the packed-micellar phase of $30 \mathrm{wt} \%$ F127/water gel, though with the major phase of packed micelles and the minor phase of polymer solution being mixed on the macroscale, a condition which at higher polymer concentrations may lead to turbid gels (Section 3.3), the exception being the gels with highest PVP concentrations ( $5 \mathrm{wt} \%$ ) which show obvious macroscopic phase separation (Section 


\subsection{Elastic Modulus ( $\left.G^{\prime}\right)$}

\subsection{1. $30 w t \% F 127$}

The temperature dependence of dynamic modulus was investigated at $f=1 \mathrm{~Hz}$ for 30 wt $\%$ solutions of F127 in water, in $0.5-10 \mathrm{wt} \%$ PEG6000/water or $0.5-5 \mathrm{wt} \%$ PEG35000/water, and in 0.1-4 wt\% PVP K30/water or PVP K90/water. At this concentration all the systems investigated were immobile (hard) gels over a wide temperature range; see Fig. 4. The rheometry of the phase separated gels with $5 \mathrm{wt} \%$ added PVP was not investigated. The resulting curves are illustrated in Fig. S5 in the Supplementary Material; typically the value of $G^{\prime}$ reached a maximum in the temperature range $37-42{ }^{\circ} \mathrm{C}$. Values of $G^{\prime \prime}$ (not shown) were low for all the gels.

The effect of adding 0.5 to $5 \mathrm{wt} \%$ polymer on the maximum value of $G^{\prime}$ is illustrated in Fig. 7. The addition of either PEG6000 or PEG35000 caused a steady decrease in $G_{\max }^{\prime}$ from $33 \mathrm{kPa}$ (water) to values below $20 \mathrm{kPa}$ ( $5 \mathrm{wt} \%$ polymer). In contrast the addition 0.1 wt $\%$ PVP K30 or PVP K90 reduced $G_{\text {max }}^{\prime}$ to values $5 \mathrm{kPa}$ or more below that obtained for F127 in water alone, but with the higher values in the range 1 to $4 \mathrm{wt} \%$ polymer showing a small decrease in $G_{\max }^{\prime}$ from $\sim 33$ to $\sim 30 \mathrm{kPa}$. Accepting, as concluded in Section 3.4, that the gel is a two-phase system in which regions of polymer solution are dispersed within the predominant packed-micellar structure of the $30 \mathrm{wt} \% \mathrm{~F} 127$ gels, the large fall in values of $G_{\text {max }}^{\prime}$ observed on addition of PEG6000 and PEG35000 implies that these polymer solutions are more effectively dispersed with the mesophase than are those of PVP K30 and PVP K90. This might be expected as it is known that PEG interacts with the E-blocks of the micelle corona in dilute solutions whereas PVP does not (see Section 3.1). 

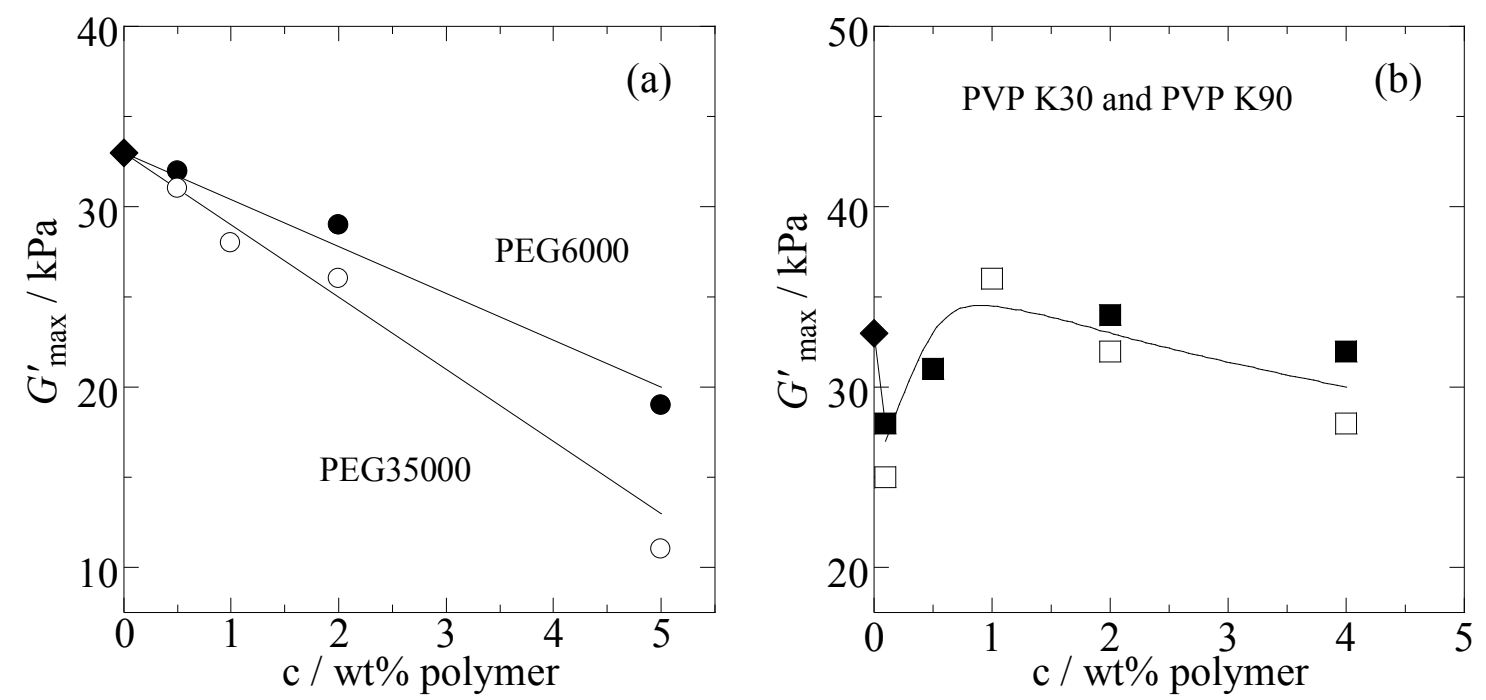

Fig. 7. The effect of added polymer on the maximum elastic moduli ( $\left.G_{\max }^{\prime}\right)$ of $30 \mathrm{wt} \% \mathrm{~F} 127$ gels. The data points refer to ( ) water alone, (a) (•) PEG6000 and (○) PEG35000, (b) PVP K30 and ( $\square$ ) PVP K90. The lines and curves are included to lead the eye through the data points

\subsection{2. $15 w t \% F 127$}

The temperature dependence of dynamic modulus was also investigated for 10, 15 and $20 \mathrm{wt} \%$ solutions of F127 in water alone and in the four polymer/water systems. The curves are shown in the Supplementary Material. $15.2 \mathrm{wt} \% \mathrm{~F} 127$ in water alone is the critical concentration for formation of the gel detected by our inverted-tube test, i.e. hard gel (see Section 3.2). The curves define regions of mobile solution with $G^{\prime}>G^{\prime \prime}$, i.e. fluid which is conveniently named soft gel as distinct from sol for which $G^{\prime \prime}>G^{\prime}$. The increase in $G^{\prime}$ is a consequence of the weak attraction of micelles as the solvent becomes poorer on heating. As seen in Figs. S6-S8 in the Supplementary Material the elastic moduli of the soft gels do not exceed $3 \mathrm{kPa}$. The transition from sol to soft gel occurs when aggregates of micelles reach a percolation threshold yielding sufficient structure to cause the characteristic rheological effect [21]. Near to the hard gel boundary the soft gel has been recognized as a defective 
version of the hard gel, i.e. structured domains in an overall fluid matrix [22].

The value of the critical soft-gel temperature $(\operatorname{csg} t)$ was conveniently obtained as the temperature at which $G^{\prime}$ first left the baseline established as the temperature was increased from $20{ }^{\circ} \mathrm{C}$. As seen in Fig. 8, the value of the csgt in the $15 \mathrm{wt} \%$ F127 solutions increased as the $w t \%$ of PEG was increased, with the effect of PEG35000 being more pronounced than that of PEG6000. Within the limited concentration range investigated, the effect on the value of the csgt of adding PVP K30 was similar to that of adding PEG6000, whereas adding PVP K90 depressed the $\operatorname{csg} t$ slightly.

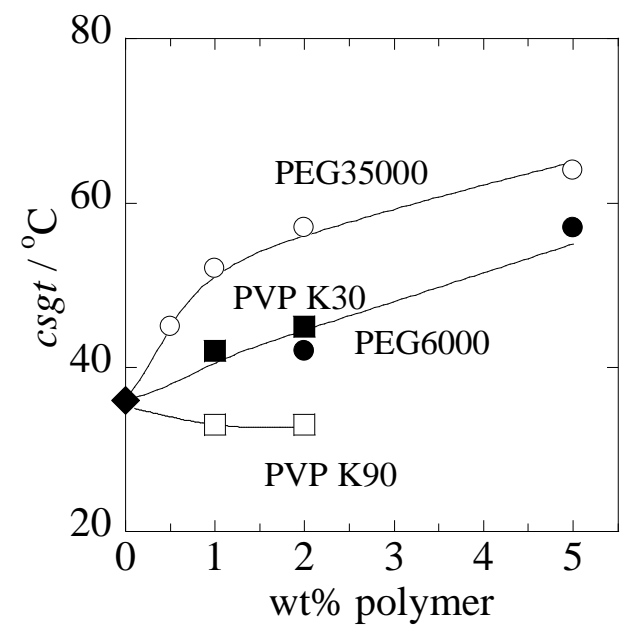

Fig. 8. The effect of added polymers on the critical temperature for soft-gel formation (csgt) in aqueous solutions of $15 \mathrm{wt} \%$ F127. The data points refer to $(\bullet)$ water alone, PEG6000, (O) PEG35000, (ם) PVP K30 and ( $\square$ ) PVP K90. The lines curves are included to lead the eye through the data points. 


\section{Concluding Remarks}

As for related copolymers $[17,18]$, dynamic light scattering served to confirm the formation of micelle clusters on adding PEG to dilute micellar solutions of copolymer F127 $(c \leq 5 \mathrm{wt} \%)$. However no effects of clustering were observed on adding PVP (see Fig.3).

In agreement with previous work by Malmsten and Lindman for F127 and PEG [12], the critical concentration for gel formation $(\mathrm{cgc})$ for F127 in water increased on addition of PEG, in our case from $15.2 \mathrm{wt} \% \mathrm{~F} 127$ for water alone to 24 or $21 \mathrm{wt} \% \mathrm{~F} 127$ on addition of 5 wt\% PEG35000 or PEG6000 respectively (see Fig. 5a). The corresponding values of the $c g c$ recorded for addition of $5 \mathrm{wt} \%$ PVP were lower: 19 and $12 \mathrm{wt} \%$ F127 for PVP K30 and PVP K90 respectively, the latter value being lower than that in water alone. The solutions with 5 wt $\%$ PVP were affected by overt phase separation, but values obtained at lower concentrations confirmed the trends.

The SAXS profiles obtained for high concentration gels (30 wt $\%$ F127) are all similar and consistent with micelles with the same hard-sphere radius and packing in the same fcc structure. We conclude that polymer solution, whether of PEG or PVP, is effectively separated from the packed-micellar phase, though with the two phases being intimately mixed on the macroscale. This view of the composition of the high-concentration $(30 \mathrm{wt} \%$ F127) gel leads to an explanation of the different effects of added PEG or PVP on the maximum elastic modulus $\left(G_{\text {max }}^{\prime}\right)$ of the gel, i.e. a steady decrease from $G_{\text {max }}^{\prime} \approx 33 \mathrm{kPa}$ observed as the concentration of PEG is increased compared with an essentially constant value of $G_{\max }^{\prime}$ as PVP is added (Fig. 7). The favourable interaction of PEG with the micelles, as indicated by micelle cluster formation in dilute solution, is consistent with PEG solution being more effective than PVP solution in penetrating the micellar phase and so lowering $G_{\max }^{\prime}$

The rheology of mobile solutions of F127 below the critical gel concentration, which 
includes regions of sol $\left(G^{\prime \prime}>G^{\prime}\right)$ and, at higher temperatures, regions of soft gel $\left(G^{\prime}>G^{\prime \prime}\right)$, is reproduced in the rheology of the F127/PEG/PVP solutions. With the exception of PVP K90, the effect of adding polymer is to raise the critical temperature for soft gel formation (Fig. 8).

Finally we note that micellar solutions of Pluronic copolymers are used for solubilisation of poorly-soluble drugs and the corresponding loaded micellar gels are used for controlled drug release $[5,23]$. In recent work we have explored the possibility of improving the solubilisation capacity of dilute micellar solutions of F127 for the drug griseofulvin by adding either PEG or PVP [13]. Our aim was to extend our knowledge of gelation of mixed copolymer/polymer systems with a view to their eventual use for drug release.

\section{Acknowledgments.}

This work was supported by CNPq, the Brazilian Research Council and INCT (N. M. P. S. R.), the PSU Research fund, Thailand (C. C.), and the Organic Materials Innovation Centre, University of Manchester. The authors thank Dr Tomás Plivelic, Ms Claire Moulton and Ms Maria Sivi for assistance with the SAXS measurements at MAX-lab, and Dr. Colin Booth for his constant help.

\section{Appendix A. Supplementary material}

Supplementary data associated with this article can be found, in the online version, at doi. 


\section{References}

[1] See, for example, P. Alexandridis, T.A. Hatton, Colloid. Surf. A 96 (1995) 1.

[2] See, for example, I.R. Schmolka, A.J. Raymond, J. Am. Oil. Chem. Soc. 42 (1967) 559.

[3] I.R. Schmolka, J. Biomed. Mater. Res. 6 (1972) 571.

[4] P.-C. Chen-Chow, S.G. Frank, Int. J. Pharm. 8 (1981) 89.

[5] (a) S.C. Chi, H.W.Jun, J. Pharm, Sci. 80 (1991) 280. (b) S. Miyazaki, T. Tobiyama, M. Takada, D. Attwood, J. Pharm. Pharmocol. 47 (1995) 455. (c) S.D. Desai, J. Blanchard, J. Phram. Sci., 87 (1998) 226. (d) M. Scherlund, A. Brodin, M. Malmsten, Int. J. Pharm. 211 (2000) 37. (e) S.S. Pisal, A.R. Paradkar, K.R. Mahadik, S.S. Kadam, Int. J. Pharm. 270 (2004) 37. (f) Y. Liu, W.-L. Liang, J.-C. Wang, X. Zhang, H. Zhang, X.-Q. Wang, T.-Y. Zhou, Q. Zhang, J. Control. Release 117 (2007) 387. (g) P.K. Sharma, M.J. Reilly, S.K. Bhatia, N. Sakhitab, J.D. Achambault, S.R. Bhatia, Colloid Surf. B 63 (2008) 229.

[6] See, for example, (a) G. Wanka, H. Hoffmann, W. Ulbricht, Colloid Polym. Sci. 268 (1990) 101. (b) C. Chaibundit, N.M.P.S. Ricardo, F. de M.L.L. Costa, S.G. Yeates, C. Booth, Langmuir 23 (2007) 9229.

[7] (a) K. Mortensen, Y. Talmon, Macromolecules 28 (1995) 8829. (b) R. Ivanova, B. Lindman, P. Alexandridis, Langmuir 16 (2000) 9058.

[8] (a) C. Wu, T. Liu, B. Chu, D.K. Schneider, V. Graziano, Macromolecules 30 (1997) 4574. (b) C. Chaibundit, Nagila M.P.S. Ricardo, Nadja M.P.S. Ricardo, C.A, Muryn, M.B. Madec, S.G. Yeates, C. Booth, J. Colloid Interface Sci., 351 (2010) 190-196.

[9] D.C. Pozzo, L.M. Walker, Macromolecules 40 (2007) 5801. J. Jiang, C. Burger, J. Li, M.Y. Lin, R.H.Colby, M.H. Rafailovich, J.C. Sokolov, Macromolecules 40 (2007) 4016.

[10] K. Mortensen, B. Batsberg, S. Hvidt, Macromolecules 41 (2008) 1720. 
[11] J.C. Gilbert, J.L. Richardson, M.C. Davies, K.J. Palin, J. Hadgraft, J. Control. Release 5 (1987) 113.

[12] M. Malmsten, B. Lindman, Macromolecules 26 (1993) 1282.

[13] C.P. Oliviera, M.E.N.P. Ribiero, N.M.P.S Ricardo, T.V. de P. Souza, C.L. Moura, C. Chaibundit, S.G. Yeates, K. Nixon, D. Attwood, Int. J. Pharm., in press.

[14] Y. Li, R. Xu, D.M. Bloor, J. Penfold, J.F. Holzwarth, E. Wyn-Jones, Langmuir, 16 (2000) 8677.

[15] C. Chaibundit, S.-M. Mai, F. Heatley, C. Booth, Langmuir 16 (2000) 9645.

[16] S.W. Provencher, Makromol. Chem. 180 (1979) 201.

[17] E. Feitosa, W. Brown, K. Wang, P.C.A. Barreleiro, Macromolecules 35 (2002) 201.

[18] L. Ge, X. Zhang, R. Guo, Polymer, 48 (2007) 2681.

[19] K.C. Tam, E. Wyn-Jones, Chem. Soc. Rev. 35 (2006) 693.

[20] (a) S.K. Nixon, S. Hvidt, C. Booth, J. Colloid Interface Sci. 280 (2004) 219. (b) G.-E. Yu, Y.-L. Deng, S. Dalton, Q.-G. Wang, D. Attwood, C. Price, C .Booth, J. Chem. Soc., Faraday Trans. 88 (1992) 2537.

[21] (a) H. Li, G.-E.Yu, C. Price, C. Booth, E. Hecht, H. Hoffmann, Macromolecules 30 (1997) 1347. (b) H. Li, G.-E. Yu, C. Price, C. Booth, J.P.A. Fairclough, A.J. Ryan, K. Mortensen, Langmuir 19 (2003) 1075.

[22] (a) R.K. Prud'homme, G. Wu, D.K. Schneider, Langmuir 12 (1996) 4651. (b) V. Castelletto, C. Caillet, J. Fundin, I.W. Hamley, Z. Yang, A. Kelarakis, J. Chem. Phys. $116(2002) 10947$.

[23] D.A. Chiappetta, A. Sosnik, Eur. J. Pharm. Biopharm. 66 (2007) 303. (b) D. Attwood, Z. Zhou, C. Booth, Expert Opinion Drug Delivery 4 (2007) 533. 